\title{
Comparison of open versus endovascular surgical treatment of abdominal aortic aneurysm
}

\begin{abstract}
Abdominal aortic aneurysm (AAA) is a common condition of increasing prevalence, particularly among older men. An AAA is defined as a permanent dilation of the abdominal aorta, with a diameter greater than $30 \mathrm{~mm}$ or a diameter greater than $50 \%$ of the aortic diameter at the level of the diaphragm. As the size of the aneurysm increases, so does the risk of rupture. Therefore, prophylactic repair with insertion of a prosthetic graft is offered. Since 1951 traditional open aneurysm repair (OAR) was reported and minimally invasive endovascular repair (EVAR) was first reported in 1986.

Data from four randomized controlled trials (EVAR-1, DREAM, OVER, ACE) for abdominal aortic aneurysm, which enrolled almost 3000 patients, in a period from 1999 to 2008, were summarized. In addition, registry databases on the treatment of AAA of average 4000 patients per year, based from 2015 to 2018 of the German Institute for Vascular Medicine Healthcare Research of the German Society for Vascular Surgery and Vascular Medicine, were compared.

The EVAR procedure for AAA showed a lower risk of perioperative mortality but was associated with a higher cardiovascular and aneurysm-related complication rate. In particular, patients aged 80 years or older benefited from EVAR since the 30-day mortality of patients receiving OAR was higher. In mid-term and long-term follow-up there were no differences in survival after endovascular and open aortic repair. Overall, it depends on the respective underlying disease and anatomy which of the two approaches is to be preferred. In conclusion, both treatment options can be considered as equal and can be offered to patients.
\end{abstract}

Keywords: abdominal aortic aneurysm, endovascular aortic repair, open aortic repair.

\footnotetext{
*Corresponding author: Sabine Kischkel: Institute for Biomedical Engineering, Rostock University Medical Center, Rostock, Germany, e-mail: sabine.kischkel@uni-rostock.de Carsten M. Bünger: Department of Vascular Medicine, Vivantes Humboldt-Klinikum, Berlin, Germany
}

https://doi.org/10.1515/cdbme-2020-3123

\section{Introduction}

An abdominal aortic aneurysm (AAA) is defined as a permanent, localized focal dilation of the aortic with an aortic diameter of $30 \mathrm{~mm}$ or greater is [1,2]. Epidemiological studies of AAA have shown an increased incidence worldwide, ranging from $4.5 \%$ to $7.7 \%$ per year $[3,4]$.

AAAs are often asymptomatic, and the size of the aneurysm has been shown to correlate with the risk of rupture $[5,6]$, which has a mortality rate of $85-95 \%$ [7]. AAA is a common disease that particularly affects men older than 60 years. As the size of the aneurysm increases the risk of rupture also increases. Risk factors include smoking, hypertension, gender, and a possible hereditary predisposition [8].

AAA is treated using two different surgical methods, endovascular placement of an aortic stent graft (EVAR) and traditional open aneurysm repair (OAR). In 1951 the OAR was first practiced as invasive treatment of AAA [6]. 40 years later the introduction of endovascular aortic repair (EVAR) was preferred as an alternative to traditional OAR for the elective repair of AAA [9]. This is primarily due to a decrease in recovery time and perioperative mortality even if an inferior late survival and higher need for re-intervention with EVAR was observed [10].

\section{Methods}

The 2018 Society of Vascular Surgery Guidelines recommend elective repair of intact AAA in asymptomatic patients with an aneurysm diameter greater than $5.4 \mathrm{~cm}$ [11].

Data from four randomized controlled trials (EVAR-1, DREAM, OVER, ACE) [10,12-14] on the treatment of asymptomatic AAA patients were randomly allocated to either minimal invasive EVAR or open surgery OAR (Table 
1). In addition, registry databases on the treatment of AAA, based from 2015 to 2018 of the German Institute for Vascular Medicine Healthcare Research of the German
Society for Vascular Surgery and Vascular Medicine, were compared [15-18].

Table 1: Randomized controlled trials for elective treatment of the abdominal aortic aneurysm (OAR versus EVAR).

\begin{tabular}{|c|c|c|c|c|c|c|c|c|}
\hline Study & \multicolumn{2}{|c|}{ EVAR-1 } & \multicolumn{2}{|c|}{ DREAM } & \multicolumn{2}{|c|}{ OVER } & \multicolumn{2}{|c|}{ ACE } \\
\hline Country & \multicolumn{2}{|c|}{ UK } & \multicolumn{2}{|c|}{ Netherlands } & \multicolumn{2}{|c|}{ USA } & \multicolumn{2}{|c|}{ France } \\
\hline Number of centres & \multicolumn{2}{|c|}{37} & \multicolumn{2}{|c|}{7} & \multicolumn{2}{|c|}{42} & \multicolumn{2}{|c|}{25} \\
\hline Period & \multicolumn{2}{|c|}{$09 / 99-08 / 04$} & \multicolumn{2}{|c|}{$11 / 00-12 / 03$} & \multicolumn{2}{|c|}{$10 / 02-04 / 08$} & \multicolumn{2}{|c|}{$03 / 05-03 / 08$} \\
\hline Follow-up (year) & \multicolumn{2}{|c|}{6} & \multicolumn{2}{|c|}{6.4} & \multicolumn{2}{|c|}{5.2} & \multicolumn{2}{|c|}{2.5} \\
\hline Treatment & OAR & EVAR & OAR & EVAR & OAR & EVAR & OAR & EVAR \\
\hline Randomized (n) & 626 & 626 & 178 & 173 & 437 & 444 & 149 & 150 \\
\hline Total & \multicolumn{2}{|c|}{1252} & \multicolumn{2}{|c|}{351} & \multicolumn{2}{|c|}{881} & \multicolumn{2}{|c|}{299} \\
\hline Age (year) & 74 & 74 & 70 & 71 & 71 & 70 & 70 & 69 \\
\hline AAA-diameter (mm) & 65 & 64 & 60 & 61 & 57 & 57 & 56 & 55 \\
\hline Men (n/\%) & $570 / 91$ & $565 / 90$ & $161 / 90$ & $161 / 93$ & $435 / 99$ & $441 / 99$ & $146 / 98$ & $150 / 100$ \\
\hline 30-day-mortality (\%) & 4.3 & 1.8 & 4.6 & 1.2 & 2.3 & 0.2 & 0.7 & 1.3 \\
\hline 2-year survival (\%) & 89 & 85 & 89 & 89 & 88 & 92 & n. i. & n. i. \\
\hline Long-term survival (\%) & 65 & 65 & 69 & 69 & 61 & 60 & n. i. & n. i. \\
\hline Re-intervention (n/\%) & $55 / 8.8$ & $145 / 23.2$ & $30 / 16.9$ & $48 / 27.7$ & $78 / 17.8$ & $98 / 22.1$ & $2 / 1.3$ & $8 / 5.3$ \\
\hline
\end{tabular}

AAA: abdominal aortic aneurysm, OAR: open aneurysm repair, EVAR: endovascular aneurysm repair, EVAR-1: The United Kingdom Endovascular Aneurysm Repair Trial 1, DREAM: The Dutch Randomized Endovascular Aneurysm Management, OVER: Open versus Endovascular Repair, ACE: Anèvrisme de l'aorte abdominale Chirurgie versus Endoprothèse, n. i.: no information.

Table 2: Registry survey on the treatment of the abdominal aortic aneurysm, based on the database from 2015 to 2018 of the German Institute for Vascular Medicine Healthcare Research of the German Society for Vascular Surgery and Vascular Medicine (OAR versus EVAR).

\begin{tabular}{|c|c|c|c|c|c|c|c|c|}
\hline Year & \multicolumn{2}{|c|}{2015} & \multicolumn{2}{|c|}{2016} & \multicolumn{2}{|c|}{2017} & \multicolumn{2}{|c|}{2018} \\
\hline Number of centres & \multicolumn{2}{|c|}{160} & \multicolumn{2}{|c|}{139} & \multicolumn{2}{|c|}{161} & \multicolumn{2}{|c|}{133} \\
\hline Treatment & OAR & EVAR & OAR & EVAR & OAR & EVAR & OAR & EVAR \\
\hline Randomized (n) & 1001 & 3767 & 641 & 2840 & 872 & 3221 & 895 & 2800 \\
\hline Total & \multicolumn{2}{|c|}{4768} & \multicolumn{2}{|c|}{3481} & \multicolumn{2}{|c|}{4093} & \multicolumn{2}{|c|}{3695} \\
\hline Age (year) & 70 & 74 & 69 & 74 & 70 & 74 & 70 & 74 \\
\hline AAA-diameter (mm) & 53 & 55 & 55 & 53 & 55 & 53 & 55 & 54 \\
\hline Men $(n / \%)$ & $826 / 83$ & $3301 / 88$ & $540 / 84$ & $2456 / 87$ & $716 / 82$ & $2789 / 87$ & $763 / 85$ & $2464 / 88$ \\
\hline 30-day-mortality (n/\%) & $54 / 5.4$ & $44 / 1.2$ & $26 / 4.1$ & $27 / 1.0$ & $34 / 3.9$ & $30 / 0.9$ & $42 / 4.7$ & $32 / 1.1$ \\
\hline Complication (n/\%) & $312 / 31.2$ & $467 / 12.4$ & $186 / 29.0$ & $317 / 11.2$ & $263 / 30.2$ & $392 / 12.2$ & $237 / 26.6$ & $400 / 13.6$ \\
\hline
\end{tabular}

AAA: abdominal aortic aneurysm, OAR: open aneurysm repair, EVAR: endovascular aneurysm repair. 


\section{Results and Conclusion}

In the four randomized controlled trials the mean diameter of AAA in EVAR and OAR was given as $60 \mathrm{~mm}$, respectively. In the German registry the mean diameter of AAA in patients who underwent EVAR was $54 \mathrm{~mm}$ versus $55 \mathrm{~mm}$ for OAR. Over $80 \%$ of the patients treated for AAA were men.

Re-interventions had to be performed in $11 \%$ of patients who underwent traditional open surgery, compared to $20 \%$ in patients who underwent minimally invasive endovascular repair. According to the data from the four randomized trials, $3 \%$ of patients died after open surgery and $1 \%$ after endovascular repair within 30 day of the intervention. This shows an advantage of EVAR after 30 days. In particular, patients older than 80 years benefit from EVAR. However, this benefit disappears after 3-4 years. In mid-term and long-term follow-up there were no differences in survival after endovascular and open aortic repair (Table 1).

Hospital mortality and complication rate for AAA with EVAR or OAR was nearly identical compared to 2015 to 2018 registry reports from the German Institute of Vascular Healthcare Research of the German Society for Vascular Surgery and Vascular Medicine. In $87 \%$ of the cases of endovascular intervention for AAA no complications occurred and $1.8 \%$ patients died within 30 days of the intervention. In $71 \%$ of the cases of open surgery for AAA no complications occurred but a total of $4.5 \%$ patients died within 30 days (Table 2 ).

With the introduction of EVAR more than twenty years ago, patients with AAA were presented with a new option for a treatment wherein a shorter hospital lay time and thus a faster return to their usual activities was observed.

Both treatment options can be considered as equal and can be offered to patients. The EVAR procedure should be the first choice of treatment of AAA in physically fit patients with suitable anatomy. OAR should be preferred when EVAR does not seem to be technically feasible or for patients where lifelong surveillance is not possible.

In conclusion, careful attention to the choice of operative strategy along with optimal treatment of medical comorbidities is critical to achieving excellent outcomes. Moreover, appropriate postoperative surveillance is necessary to minimize subsequent aneurysm-related death or morbidity [11].

\section{Author Statement}

This work was supported by the Federal Ministry of Education and Research, within RESPONSE "Partnership for Innovation in Implant Technology", Germany Grant Number 03ZZ0904A. Authors state no conflict of interest.

\section{References}

[1] Ren S, Fan X, Ye Z, Liu P. Long-term outcomes of endovascular repair versus open repair of abdominal aortic aneurysm. Ann Thorac Cardiovasc Surg. 2012;18:222-7.

[2] Takayama T, Yamanouchi D. Aneurysmal disease: the abdominal aorta. Surg Clin North Am. 2013;93:877-91, viii.

[3] Dua A, Kuy S, Lee CJ, Upchurch GR, Desai SS. Epidemiology of aortic aneurysm repair in the United States from 2000 to 2010. J Vasc Surg. 2014;59:1512-7.

[4] Collaborative Aneurysm Screening Study Group (CASS Group)Chichester Aneurysm Screening Group (UK)Viborg Aneurysm Screening Study. A comparative study of the prevalence of abdominal aortic aneurysms in the United Kingdom, Denmark, and Australia. J Med Screen. 2001;8:46-50.

[5] Dubost C, Allary M, Oeconomos N. A propos du traitement des anévrysmes de l'aorte; ablation de l'anévrysme; rétablissement de la continuité par greffe d'aorte humaine conservée. Mem Acad Chir (Paris). 1951;77:381-3.

[6] Greenhalgh RM, Brown LC, Powell JT, Thompson SG, Epstein D, Sculpher MJ. Endovascular versus open repair of abdominal aortic aneurysm. N Engl J Med. 2010;362:1863-71.

[7] Akkersdijk GJ, Puylaert JB, Vries AC de. Abdominal aortic aneurysm as an incidental finding in abdominal ultrasonography. Br J Surg. 1991;78:1261-3.

[8] Legg JS, Legg LM. Abdominal Aortic Aneurysms. Radiologic technology. 2016;88:145-63.

[9] Parodi JC, Palmaz JC, Barone HD. Transfemoral intraluminal graft implantation for abdominal aortic aneurysms. Ann Vasc Surg. 1991;5:491-9.

[10] Patel R, Sweeting MJ, Powell JT, Greenhalgh RM. Endovascular versus open repair of abdominal aortic aneurysm in 15-years' follow-up of the UK endovascular aneurysm repair trial 1 (EVAR trial 1): a randomised controlled trial. The Lancet. 2016;388:2366-74.

[11] Chaikof EL, Dalman RL, Eskandari MK, Jackson BM, Lee WA, Mansour MA, et al. The Society for Vascular Surgery practice guidelines on the care of patients with an abdominal aortic aneurysm. J Vasc Surg. 2018;67:277.e2.

[12] Bruin JL de, Baas AF, Buth J, Prinssen M, Verhoeven ELG, Cuypers PWM, et al. Long-term outcome of open or endovascular repair of abdominal aortic aneurysm. $\mathrm{N}$ Engl J Med. 2010;362:1881-9.

[13] Lederle FA, Freischlag JA, Kyriakides TC, Matsumura JS, Padberg FT, Kohler TR, et al. Long-term comparison of endovascular and open repair of abdominal aortic aneurysm. N Engl J Med. 2012;367:1988-97. 
[14] Becquemin J-P, Pillet J-C, Lescalie F, Sapoval M, Goueffic $Y$, Lermusiaux $P$, et al. A randomized controlled trial of endovascular aneurysm repair versus open surgery for abdominal aortic aneurysms in low- to moderate-risk patients. J Vasc Surg. 2011;53:11671173.e1.

[15] Schmitz-Rixen T, Keese M, Hakimi M, Peters A, Böckler D, Nelson K, Grundmann RT. Ruptured abdominal aortic aneurysm - epidemiology, predisposing factors, and biology. Langenbecks Arch Surg. 2016;401:275-88.
[16] Schmitz-Rixen T, Steffen M, Grundmann RT. Versorgung des abdominellen Aortenaneurysmas (AAA) 2016. Gefässchirurgie. 2018;23:174-84.

[17] Schmitz-Rixen T, Steffen M, Böckler D, Grundmann RT. Versorgung des abdominellen Aortenaneurysmas (AAA) 2017. Gefässchirurgie. 2019;24:162-72.

[18] Schmitz-Rixen T, Steffen M, Böckler D, Grundmann RT. Versorgung des abdominellen Aortenaneurysmas (AAA) 2018. Gefässchirurgie. 2020;25:117-23. 